\title{
Optimization of friction stir processing parameters for enhanced microhardness of AA5083/Al-Fe in-situ composites via Taguchi technique
}

\author{
Vivek Kumar Jain ${ }^{1}$, Manoj Kumar Yadav ${ }^{2}$, Arshad Noor Siddiquee ${ }^{3}$, Zahid A. Khan ${ }^{4}$ \\ ${ }^{1}$ Department of Mechanical Engineering, IMS Engineering College, Ghaziabad (UP), 201013, India \\ ${ }^{2}$ Department of Mechanical Engineering, Inderprastha Engineering College, \\ Ghaziabad (UP), 201010, India \\ ${ }^{3,4}$ Department of Mechanical Engineering, Jamia Millia Islamia, New Delhi, 110025, India \\ ${ }^{1}$ Corresponding author \\ E-mail: ${ }^{1}$ vivekjain124@gmail.com, ${ }^{2}$ manojkyadav@gmail.com, ${ }^{3}$ arshadnsiddiqui@gmail.com, \\ 4zahidjmi@yahoo.com
}

Received 1 August 2021; received in revised form 19 August 2021; accepted 1 September 2021 DOI https://doi.org/10.21595/msea.2021.22179

Check for updates

Copyright $\circledast 2021$ Vivek Kumar Jain, et al. This is an open access article distributed under the Creative Commons Attribution License, which permits unrestricted use, distribution, and reproduction in any medium, provided the original work is properly cited.

\begin{abstract}
Friction stir processing (FSP) is a novel technique to fabricate metal matrix composites (MMCs) and surface composites (SCs). In the present study, Taguchi's technique is used for attaining the optimum value of microhardness for AA5083/Al-Fe in-situ surface composites (SCs) via FSP using 40 hours mechanical alloyed Fe-40wt $\%$ Al powder mixture. Three different process parameters i.e. tool shoulder diameter, tool rotational speed, and tool traverse speed each having three levels were selected for optimizing the microhardness of SCs. The experimental study was accomplished by employing Taguchi's L9 orthogonal array. The Microhardness of the fabricated composites was confirmed using Vickers tester after the single-pass FSP. The outcomes of the study were examined and studied using signal to noise $(\mathrm{S} / \mathrm{N})$ ratio. The analysis also confirms the results and displayed that the optimum value of microhardness of $123.3 \mathrm{Hv}$ was obtained with the selected parameter of tool shoulder diameter of $21 \mathrm{~mm}$, tool rotational speed of $900 \mathrm{rpm}$, and traverse speed of $63 \mathrm{~mm} / \mathrm{min}$.
\end{abstract}

Keywords: friction stir processing, microhardness, Taguchi orthogonal array, process parameters.

\section{Introduction}

In recent years in search of advanced structural materials, most of the researchers work in line on admirable substitute of conformist materials such as steel with aluminum alloys as the alternative due to their outstanding specific strength, high strength to weight ratio, good formability, high thermal and electrical conductivity, good corrosion resistance, machinability, and weldability, etc. [1]. Structural steel was used as a conventional material for more than 150 years in the area of transportation and shipbuilding industry because of its outstanding mechanical properties with low cost of manufacturing. But due to the increased demand in the areas of construction of the bigger ships, engineers had to hunt for substitute materials in this direction to decrease the weight of ships. Aluminum and its alloys were evaluated as the most possible substitute for steel, due to their high corrosion resistance and low weight to high strength. But due to the lower strength aluminum, its wide applications were restricted. Composites in the form of a metal matrix or surface composites show improved mechanical properties. These composites could be manufactured by different approaches such as casting process, mechanical alloying [2], laser sintering methods [3], high-energy electron beam irradiation [4], plasma spraying [5], cast sinter [6] friction stir processing (FSP) [7], etc. However, these methods suffer certain disadvantages like underprivileged interfacial bonding amongst the metal matrix and reinforcement particles, the formation of high strain in the fabricated composite due to crystal structure mismatching, and surface contamination [8]. As well, most of these methods are based on liquid-phase processing which gives intermetallic reactions and obnoxious phases within base 
metal (BM) and reinforcement [9], [10]. Thus, based on the above limitations there is a need for a process that will be performed in solid-state condition, produce proper interfacial bonding between metal matrix and reinforcement along with capable of producing homogeneous dispersion of reinforcements within. Therefore, in-situ composites fabricated through FSP were a capable way to produce this. FSP was developed by Mishra et al. at "The Welding Institute (TWI), UK" in 1991 and based on principles of friction stir welding (FSW), for surface modification of materials [11], [12]. FSP is a solid-state novel technique and is widely used for enhancing the mechanical properties of the substrate material by refinement of the microstructure and homogenization of the structure [13]. During the FSP process, a cylindrical tool having a pin and shoulder is introduced in the substrate plate and rotates about its axis, and moved along its intended path as shown in Fig. 1. In FSP, the frictional heat is obtained by a combination of rubbing action of the tool shoulder and metal matrix, rotational and traverse speed which soften the processed material and are experienced by severe plastic deformation (SPD). During the process, the stirring action of the rotating tool moves the material around the tool, and as a result, severe plastic deformation was obtained in the processed region [14], [15].

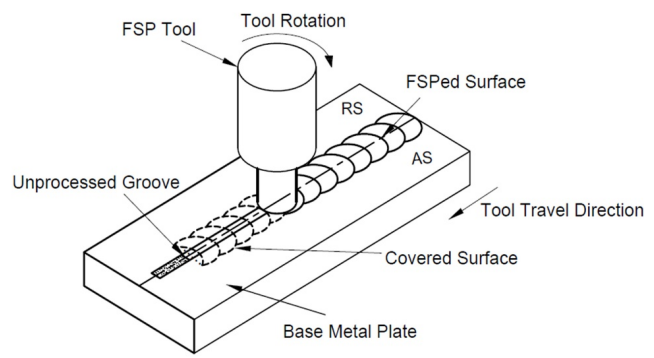

Fig. 1. Schematic diagram of FSP technique.

In this direction, Aluminium alloy 5083-H111 has wider engineering applications in fast sea transportation for commercial and military applications, such as military vehicles and high-performance vessels [16], [17], aerospace, marine, transportation, and structural applications due to its low density, high strength to weight ratio, outstanding weldability, excellent corrosion resistance, good formability, and moderate to high strength. Additionally, AA5083 has extremely high toughness both at room and cryogenic temperatures, its tensile strengths, elastic moduli, and fatigue properties at cryogenic temperature are as high as, or even higher than those at room temperature [18].

Previous literature shows that tool shoulder diameter, tool rotational speed, and tool traverse speed are some of the important FSP process parameters which show a great influence in the distribution of reinforcement, refinement of the grains, and generation of heat and final mechanical properties of the fabrication composites [19].

Several researchers developed SCs via using different reinforcements such as $\mathrm{SiC}$ [20], [21], $\mathrm{Al}_{2} \mathrm{O}_{3}$ [22], $\mathrm{TiC}$ [23], $\mathrm{TiO}_{2}$ [26] [27], $\mathrm{Al}_{3} \mathrm{Ni}$ [14], $\mathrm{B}_{4} \mathrm{C}$ [26] etc. During the study, different researchers tell us that some of the reinforcement react with the metal matrix and form in-situ composites [27]-[29]. In this direction, SCs of AA5083/Al-Fe in situ composites via FSP are fabricated and the effect of these three process parameters on the micro-hardness of fabricated SCs is analyzed. Taguchi design of experiments along with MiniTab is used for evaluating the experimental design and understanding of data respectively.

\section{Experimental procedure}

In the present study, the base material employed is a $6.3 \mathrm{~mm}$ thick AA 5083-H111 alloy sheet of $200 \mathrm{~mm}$ long and $80 \mathrm{~mm}$ width. The chemical composition of base metal (BM) is represented in Table 1. To produce SCs, a square groove of $2.5 \mathrm{~mm}^{2}$ was machined in the center of the substrate plate along the length direction. Mechanical alloyed reinforcement $\left(\mathrm{Fe}_{60} \mathrm{Al}_{40}\right)$ having an 
average grain size of $\sim 10 \mu \mathrm{m}$, was filled and compacted into the square groove and packed using a pinless tool of $14 \mathrm{~mm}$ shoulder diameter to prevent the spluttering of the reinforcement powder mixture. Finally, the FSP run was done at room temperature through a retrofitted type robust vertical milling machine (VMM). During the experimentation $\mathrm{H}-13$ tool steel having a cylindrical tool pin and a tool shoulder with ACW (anti-clockwise) spiral scroll $(0.75 \mathrm{~mm}$ scroll width and $0.5 \mathrm{~mm}$ scroll depth), $6.5 \mathrm{~mm}$ pin diameter, $3.5 \mathrm{~mm}$ pin height, and $1.5^{\circ}$ tool tilt angle was used for the experimentation as portrayed in Figure 2. The purpose of providing the ACW spiral scroll is to guide the plasticized material from the boundary to the axis of the metal matrix [19].

Table 1. Compositional analysis of AA5083-H111 substrate plate

\begin{tabular}{|c|c|c|c|c|c|c|c|c|c|}
\hline Element & $\mathrm{Mg}$ & $\mathrm{Mn}$ & $\mathrm{Fe}$ & $\mathrm{Cr}$ & $\mathrm{Si}$ & $\mathrm{Ti}$ & $\mathrm{Zn}$ & $\mathrm{Cu}$ & $\mathrm{Al}$ \\
\hline AA5083-H111 & 4.82 & 0.55 & 0.213 & 0.096 & 0.043 & 0.013 & 0.011 & 0.009 & Remaining \\
\hline
\end{tabular}

Using Taguchi L9 orthogonal array nine different experiments were performed. Tool shoulder diameter $(\mathrm{mm})$, tool rotational speed $(\mathrm{rpm})$, and tool traverse speed $(\mathrm{mm} / \mathrm{min})$ were the parameters under consideration. The range of FSP parameters was selected through rigorous pilot trials made on AA5083 and shown in Table 2.

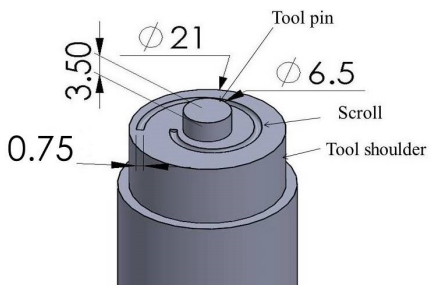

Fig. 2. FSP tool with cylinder pin and shoulder scroll

After performing a single FSP pass, the test coupon was cut from the processed region perpendicular to the FSP path with wire EDM and prepared for mechanical characterization. Then the samples were polished using emery grade papers with the standard metallographic procedure. Standard modified Poulton's reagent was used as an etchant for $10 \mathrm{sec}$. Microhardness measurements of a processed zone of samples were dignified $1 \mathrm{~mm}$ underneath the upper surface with $0.5 \mathrm{~mm}$ spacing in the horizontal direction on Vickers microhardness tester at a force of $9.81 \mathrm{~N}$ for a dwell of 25 seconds. Two different repetitions were done to measure the microhardness value at different positions and then average values were used for the analysis.

Table 2. Range of selected parameters for single-pass FSP

\begin{tabular}{|c|c|c|c|c|}
\hline \multirow{2}{*}{ Sign } & \multirow{2}{*}{ Selected parameters } & \multicolumn{3}{|c|}{ Level } \\
\cline { 3 - 5 } & & 1 & 2 & 3 \\
\hline T1 & Tool shoulder diameter (TSD, $\mathrm{mm})$ & 16 & 18.5 & 21 \\
\hline T2 & Tool rotational speed (TRS, rpm) & 710 & 900 & 1120 \\
\hline T3 & Tool traverse speed (TTS, $\mathrm{mm} / \mathrm{min})$ & 63 & 80 & 100 \\
\hline
\end{tabular}

Table 3. Experimental layout L9 orthogonal array

\begin{tabular}{|c|c|c|c|c|c|c|}
\hline Exp. No. & T1 & T2 & T3 & Sample code & Micro hardness value (Hv) & S/N ratio \\
\hline 1 & 1 & 1 & 1 & $\mathrm{~S}_{1}$ & 97.7 & 39.798 \\
\hline 2 & 1 & 2 & 3 & $\mathrm{~S}_{2}$ & 94 & 39.463 \\
\hline 3 & 1 & 3 & 2 & $\mathrm{~S}_{3}$ & 99.5 & 39.956 \\
\hline 4 & 2 & 1 & 3 & $\mathrm{~S}_{4}$ & 100.7 & 40.061 \\
\hline 5 & 2 & 2 & 2 & $\mathrm{~S}_{5}$ & 100.3 & 40.026 \\
\hline 6 & 2 & 3 & 1 & $\mathrm{~S}_{6}$ & 98.5 & 39.869 \\
\hline 7 & 3 & 1 & 2 & $\mathrm{~S}_{7}$ & 98.9 & 39.904 \\
\hline 8 & 3 & 2 & 1 & $\mathrm{~S}_{8}$ & 123.3 & 41.819 \\
\hline 9 & 3 & 3 & 3 & $\mathrm{~S}_{9}$ & 103.2 & 40.274 \\
\hline
\end{tabular}




\section{Results and discussion}

\subsection{Signal to noise ratio $(\mathrm{S} / \mathrm{N})$}

On the way to find the effect of FSP process parameters on the fabricated SCs Signal-to-Noise ratio $(S / N)$ and Analysis of Signal to Noise $(S / N)$ ratio is assessed for each level of process parameters [30]. Maximum microhardness value is required for high strength and wear characteristics of the SCs, so higher-the-better value characteristics conforming to a greater $S / N$ ratio and optimum FSP parameter level were evaluated. $S / N$ ratio predicts the importance and ideal amalgamation of FSP parameters. $S / N$ ratios for all the nominated parameters were premeditated for variance minimization in micro-hardness test value. $S / N$ ratio principally reveals the experimental output sensitiveness to the noise factors. In this study principle of higher is the better is selected for ideal response and was intended conferring to the Eq. (1) [31], [32]:

$$
\frac{S}{N}=-10 \log \left(\frac{1}{n} \sum_{i=1}^{3} \frac{1}{Y_{i}^{2}}\right),
$$

whereas $n$ is the number of repetitions and $Y_{i}$ is the response value at an $i$ th level. $S / N$ ratio for each combination of process parameters was represented in Table 3.
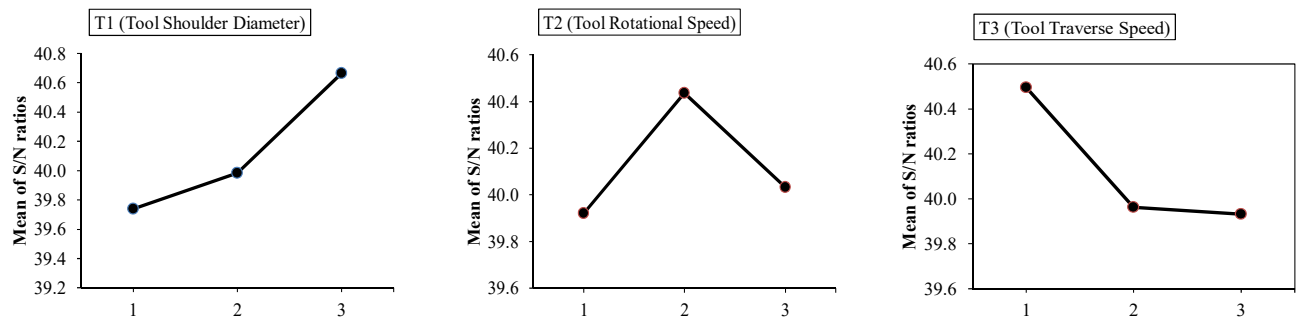

Fig. 3. Main effect plots for signal to noise ratios

The maximum hardness value was attained when T1, T2, and T3 were selected as $21 \mathrm{~mm}$, $900 \mathrm{rpm}$, and $63 \mathrm{~mm} / \mathrm{min}$ respectively. The significance of FSP parameters i.e. T1, T2, and T3 on $S / N$ ratio and mean of hardness responses were represented in Fig. 3 and Fig. 4.
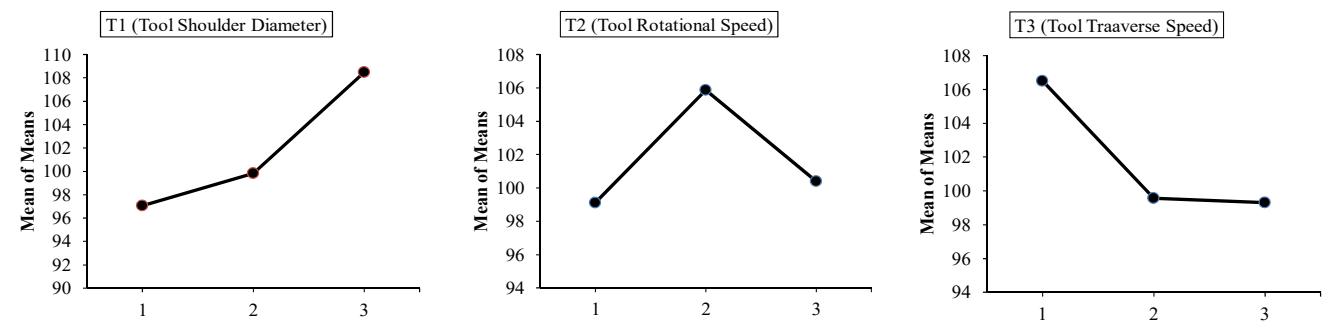

Fig. 4. Mean of hardness values plot

\subsection{Microhardness}

The average microhardness of each fabricated SCs was much higher as compared to the AA5083 substrate plate i.e. 81.9 Hv. Obtained results show that at different FSP parameters there was a significant alteration in the hardness values as compared to substrate metal. Reasons for the increase in micro-hardness values are in-situ reaction promotes at elevated temperature, refinement of grain, uniform dispersion of reinforcement in a metal matrix, formation of fine grains per Hall-Petch relationship, and pinning effect produce at grain boundaries. 


\section{Conclusions}

In the present study, in-situ AA5083/Al-Fe surface composites were successfully fabricated using single-pass FSP, and the effect of process parameters on the microhardness of the SCs was evaluated. The summary of the paper is represented below:

1) During FSP metal matrix particles were disintegrated under high plastic strains and stirring action of the FSP tool in the processed zone.

2) High temperature produced during the process promotes the in-situ reaction between metal matrix particles and reinforcement which further improves the microhardness of the fabricated composites.

3) Using the Taguchi technique optimum combination of FSP parameters that affect the micro-hardness of AA5083/Al-Fe SCs can be identified with a minimum number of experiments.

4) The obtained results show that for a combination of $21 \mathrm{~mm}$ tool shoulder, $900 \mathrm{rpm}$ tool rotational speed, and $63 \mathrm{~mm} / \mathrm{min}$ tool traverse speed produces maximum hardness of about 123.3 Hv in the processed zone.

5) The maximum hardness value was $50.55 \%$ more than the BM.

\section{References}

[1] D. Miracle, "Metal matrix composites - From science to technological significance," Composites Science and Technology, Vol. 65, No. 15-16, pp. 2526-2540, Dec. 2005, https://doi.org/10.1016/j.compscitech.2005.05.027

[2] C. Suryanarayana and I.-S. An, "Mechanical alloying and milling," Journal of Korean Powder Metallurgy Institute, Vol. 13, No. 5, pp. 371-372, Oct. 2006, https://doi.org/10.4150/kpmi.2006.13.5.371

[3] M. K. Yadav, A. N. Siddiquee, and Z. A. Khan, "Fabrication of promising material "titanium aluminide': methods and issues (a status report)," Materials Research Express, Vol. 5, No. 11, p. 116504, Sep. 2018, https://doi.org/10.1088/2053-1591/aadb2a

[4] S.-H. Choo, S. Lee, and S.-J. Kwon, "Effect of flux addition on the microstructure and hardness of TiC-reinforced ferrous surface composite layers fabricated by high-energy electron beam irradiation," Metallurgical and Materials Transactions A, Vol. 30, No. 12, pp. 3131-3141, Dec. 1999, https://doi.org/10.1007/s11661-999-0224-4

[5] M. Gui and S. B. Kang, "6061 Al/Al-SiCp bi-layer composites produced by plasma-spraying process," Materials Letters, Vol. 46, No. 5, pp. 296-302, Dec. 2000, https://doi.org/10.1016/s0167$577 \mathrm{x}(00) 00191-9$

[6] Y. Wang, X. Zhang, G. Zeng, and F. Li, "Cast sinter technique for producing iron base surface composites," Materials and Design, Vol. 21, No. 5, pp. 447-452, Oct. 2000, https://doi.org/10.1016/s0261-3069(00)00036-4

[7] M. K. Yadav, A. N. Siddiquee, and Z. A. Khan, "Characterization of Ti-Al intermetallic synthesized by mechanical alloying process," Metals and Materials International, Vol. 27, No. 7, pp. 2378-2386, Jul. 2021, https://doi.org/10.1007/s12540-019-00603-w

[8] Scott V. D., "An introduction to metal matrix composites," Composites Science and Technology, Vol. 51, pp. 121-130, 1987.

[9] R. S. Mishra and M. W. Mahoney, Friction Stir Welding and Processing. ASM International, 2007.

[10] R. S. Mishra and Z. Y. Ma, "Friction stir welding and processing," Materials Science and Engineering: R: Reports, Vol. 50, No. 1-2, pp. 1-78, Aug. 2005, https://doi.org/10.1016/j.mser.2005.07.001

[11] C. J. D. W. M. Thomas, E. D. Nicholas, J. C. Needham, M. G. Murch, and P. Templesmith, "Improvements to friction welding," International Patent Application PCT/GB92/02203 and GB Patent Application No.9125978.8, 1991.

[12] T. Majeed, M. A. Wahid, M. N. Alam, Y. Mehta, and A. N. Siddiquee, "Friction stir welding: A sustainable manufacturing process," Materials Today: Proceedings, Vol. 46, pp. 6558-6563, 2021, https://doi.org/10.1016/j.matpr.2021.04.025

[13] S. Mironov, Y. S. Sato, and H. Kokawa, "Friction-stir processing," in Nanocrystalline Titanium, Elsevier, 2019, pp. 55-69, https://doi.org/10.1016/b978-0-12-814599-9.00004-3

[14] A. Shahi, M. H. Sohi, D. Ahmadkhaniha, and M. Ghambari, "In situ formation of Al-Al3Ni composites on commercially pure aluminium by friction stir processing," The International Journal of Advanced 
Manufacturing Technology, Vol. 75, No. 9-12, pp. 1331-1337, Dec. 2014, https://doi.org/10.1007/s00170-014-6162-3

[15] P. Goel et al., "Investigation on material mixing during FSW of AA7475 to AISI304," Materials and Manufacturing Processes, Vol. 34, No. 2, pp. 192-200, Jan. 2019, https://doi.org/10.1080/10426914.2018.1544717

[16] T. Anderson, "The history of aluminum welding," Svetsaren, Vol. 59, No. 1, pp. 60-62, Jan. 2004.

[17] A. Piers Newbery, S. R. Nutt, and E. J. Lavernia, "Multi-scale Al 5083 for military vehicles with improved performance," JOM, Vol. 58, No. 4, pp. 56-61, Apr. 2006, https://doi.org/10.1007/s11837006-0216-4

[18] N. S. Raghavendran, M. E. Fourney, and F. V. Lawrence, "Fatigue-fracture behavior of 5083-0 aluminum-magnesium alloy for LNG applications," Engineering Fracture Mechanics, Vol. 29, No. 6, pp. 647-662, Jan. 1988, https://doi.org/10.1016/0013-7944(88)90167-1

[19] N. Gangil, S. Maheshwari, and A. N. Siddiquee, "Influence of tool pin and shoulder geometries on microstructure of friction stir processed AA6063/SiC composites," Mechanics and Industry, Vol. 19, No. 2, p. 211, 2018, https://doi.org/10.1051/meca/2018010

[20] J. Tang, Y. Shen, and J. Li, "Influences of friction stir processing parameters on microstructure and mechanical properties of SiC/Al composites fabricated by multi-pin tool," Journal of Manufacturing Processes, Vol. 38, pp. 279-289, Feb. 2019, https://doi.org/10.1016/j.jmapro.2019.01.029

[21] A. Dolatkhah, P. Golbabaei, M. K. Besharati Givi, and F. Molaiekiya, "Investigating effects of process parameters on microstructural and mechanical properties of $\mathrm{Al} 5052 / \mathrm{SiC}$ metal matrix composite fabricated via friction stir processing," Materials and Design, Vol. 37, pp. 458-464, May 2012, https://doi.org/10.1016/j.matdes.2011.09.035

[22] S. S. Mohamed, "Microstructure and mechanical properties of AA2024/A12O3 Surface nanocomposites fabricated using friction stir processing," Journal of Engineering Research, Vol. 1, pp. 1-6, 2018.

[23] A. Thangarasu, N. Murugan, I. Dinaharan, and S. J. Vijay, "Microstructure and microhardness of AA1050/TiC surface composite fabricated using friction stir processing," Sadhana, Vol. 37, No. 5, pp. 579-586, Oct. 2012, https://doi.org/10.1007/s12046-012-0097-x

[24] R. Beygi, M. Z. Mehrizi, and G. Eisaabadi B., "Friction stir processing of Al with mechanically alloyed Al-TiO2-graphite powder: microstructure and mechanical properties," Journal of Materials Engineering and Performance, Vol. 26, No. 3, pp. 1455-1462, Mar. 2017, https://doi.org/10.1007/s11665-017-2552-7

[25] V. C. Gudla, F. Jensen, A. Simar, R. Shabadi, and R. Ambat, "Friction stir processed Al-TiO2 surface composites: Anodising behaviour and optical appearance," Applied Surface Science, Vol. 324, pp. 554-562, Jan. 2015, https://doi.org/10.1016/j.apsusc.2014.10.151

[26] H. G. Rana, V. J. Badheka, and A. Kumar, "Fabrication of A17075 / B4C surface composite by novel friction stir processing (FSP) and investigation on wear properties," Procedia Technology, Vol. 23, pp. 519-528, 2016, https://doi.org/10.1016/j.protcy.2016.03.058

[27] F. Khodabakhshi, A. Simchi, A. H. Kokabi, and A. P. Gerlich, "Friction stir processing of an aluminum-magnesium alloy with pre-placing elemental titanium powder: In-situ formation of an Al3Ti-reinforced nanocomposite and materials characterization," Materials Characterization, Vol. 108, pp. 102-114, Oct. 2015, https://doi.org/10.1016/j.matchar.2015.08.016

[28] E. Basiri Tochaee, H. R. Madaah Hosseini, and S. M. Seyed Reihani, "Fabrication of high strength insitu Al-Al3Ti nanocomposite by mechanical alloying and hot extrusion: Investigation of fracture toughness," Materials Science and Engineering: A, Vol. 658, pp. 246-254, Mar. 2016, https://doi.org/10.1016/j.msea.2016.02.010

[29] E. Basiri Tochaee, H. R. Madaah Hosseini, and S. M. Seyed Reihani, "On the fracture toughness behavior of in-situ Al-Ti composites produced via mechanical alloying and hot extrusion," Journal of Alloys and Compounds, Vol. 681, pp. 12-21, Oct. 2016, https://doi.org/10.1016/j.jallcom.2016.04.111

[30] M. A. Wahid, N. Sharma, P. Goel, A. Mohsin, and A. Singh, "Friction stir welding of AA 8011: mechanical and microstructure behavior," in Lecture Notes on Multidisciplinary Industrial Engineering, Singapore: Springer Singapore, 2020, pp. 129-138, https://doi.org/10.1007/978-981-329099-0_14

[31] M. Srivastava, A. N. Siddiquee, S. Rathee, and S. Maheshwari, "Optimisation of friction stir processing parameters to fabricate AA6063/SiC surface composites using Taguchi technique," International Journal of Materials and Product Technology, Vol. 58, No. 1, p. 16, 2019, https://doi.org/10.1504/ijmpt.2019.10017760 
[32] D. Ahmadkhaniha, M. Heydarzadeh Sohi, A. Zarei-Hanzaki, S. M. Bayazid, and M. Saba, "Taguchi optimization of process parameters in friction stir processing of pure Mg," Journal of Magnesium and Alloys, Vol. 3, No. 2, pp. 168-172, Jun. 2015, https://doi.org/10.1016/j.jma.2015.04.002

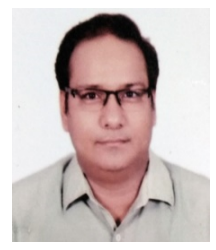

Mr. Vivek Kumar Jain is an Assistant Professor in the Department of Mechanical Engineering at IMS Engineering College, Ghaziabad, (U.P.), India. Currently he is pursuing Ph.D. from Jamia Millia Islamia (A Central University), New Delhi, India under the guidance of Dr. Arshad Noor Siddiquee and Dr. Zahid Akhtar Khan.

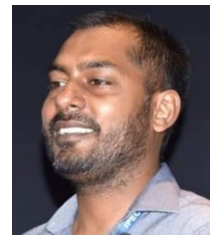

Mr. Manoj Kumar Yadav is an Assistant Professor in the Department of Mechanical Engineering at IPEC, Ghaziabad, (U.P.), India. Currently he is pursuing Ph.D. from Jamia Millia Islamia (A Central University), New Delhi, India under the guidance of Dr. Arshad Noor Siddiquee and Dr. Zahid Akhtar Khan.

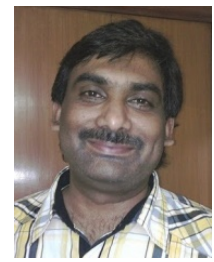

Dr. Arshad Noor Siddiquee is a Professor in the Department of Mechanical Engineering at Jamia Millia Islamia (A Central University), New Delhi, India. He earned Ph.D. and M. Tech from IIT Delhi. He has supervised several M. Tech dissertations and currently, he is supervising 10 doctoral research scholars. His major research interest includes material structure-property correlation, materials processing, welding engineering, machining and optimization of design and process parameters. He has published more than 90 articles in reputed journals and conference proceedings. He has also co-authored four books related to engineering and one monograph as well.

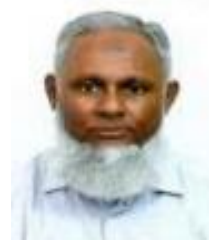

Dr. Zahid Akhtar Khan is a Professor in the Department of Mechanical Engineering at Jamia Millia Islamia (A Central University), New Delhi, India. He earned Ph.D. Jamia Millia Islamia, New Delhi. He has supervised several M. Tech dissertations and currently, he is supervising 12 doctoral research scholars. His major research interest includes production and industrial engineering, metal machining, friction stir welding/Processing, optimization of design and manufacturing processes parameters, multi criteria decision making (MCDM), ANN \& fuzzy modelling, ergonomics/human factors engineering. He has published more than 161 articles in reputed journals and conference proceedings. He has also co-authored eight books related to engineering and two monograph and four patents as well. 